\title{
Lipoprotein Profile in Canine Pancreatitis Induced with Oleic Acid
}

\author{
Toshiya CHIKAMUNE, Hiromu KATAMOTO, Koichi NOMURA and Fumihito OHASHI \\ Department of Veterinary Surgery, College of Agriculture, Osaka Prefecture University, 1-1 Gakuen-cho, Sakai, Osaka 593, Japan
}

(Received 12 March 1996/Accepted 26 November 1997)

\begin{abstract}
Lipid and lipoprotein concentrations and apolipoprotein profile were investigated in canine pancreatitis induced by infusion with oleic acid (OA) into the accessory pancreatic duct. Pancreatitis was diagnosed by physical, hematological, biochemical and pathological examinations. In OA-treated dogs, serum triglyceride (TG) concentration was increased; however, there were no changes in serum total cholesterol (TC) and phospholipid (PL) concentrations. Serum concentrations of TG, TC, PL and total lipids (TL) in beta

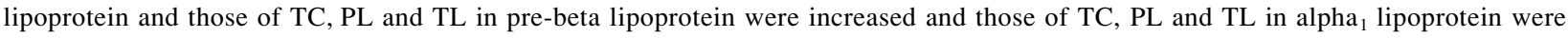
decreased. In apolipoprotein profile, the proportions of apolipoprotein B100 in low density lipoprotein fraction and apolipoprotein A-IV in high density lipoprotein fraction were increased. In addition, decreased proportion of apolipoprotein A-I and the appearance of serum amyloid A protein in high density lipoprotein fraction were observed. These results suggest that lipoprotein profiles observed in canine acute pancreatitis are attributed to the alterations in apolipoprotein compositions. - KEY wORDS: apolipoprotein, canine, lipid, lipoprotein, pancreatitis.
\end{abstract}

Canine hyperlipidemia is a secondary finding in diabetes mellitus [3, 15], hypothyroidism [3, 15], hyperadrenocorticism [3] and acute pancreatitis [15, 27]. There is a low incidence of acute pancreatitis but a high mortality. The mechanisms responsible for the occurrence of acute pancreatitis are not well understood. Pancreatic duct obstruction [9, 17], dietary factor [9, 17, 21], infectious agents [9, 17], trauma [17], hypercalcemia [9, 17, 21], hyperlipidemia $[9,17,21]$, vascular factors $[9,17,21]$, drugs $[9,17,21]$ and hereditary factors [21] are reported as causative factors of acute pancreatitis.

Havel [10] has reported that pancreatitis can be preceded by a hypertriglyceridemia. The initial process of pancreatitis has been proposed as follows. Triglyceride (TG) in the circulation undergoes hydrolysis by a pancreatic lipase to free fatty acids and glycerol. Although free fatty acids are bound to albumin in normal condition, quantities of unbound fatty acids increase in hypertriglyceridemia. Free fatty acids are bipolar lipids with high surface activity and may destroy cellular membranes by their detergent effect [18]. The development of acute pancreatitis followed by hypertriglyceridemia is reported in dogs [27].

Recently, the number of obese dogs has increased because of overnutrition by a loose feeding management and a lack of exercise [11]. Consequently, there has been a high incidence of diseases related to obesity [7]. The dogs with pancreatitis are often obese [1] and we observed hypertriglyceridemia in obese dogs [7]. In addition, obesity might be a predisposition to acute pancreatitis [7]. These investigations suggest that hyperlipidemia coming from high fat diet or obesity may cause acute pancreatitis in dogs.

Canine lipid and lipoprotein profiles have been reported in pancreatitis induced by ligation of pancreatic duct [4], infusion with mixture of bile and trypsin [27] and in clinical cases [15, 27]. While increased concentrations of TG and beta lipoprotein (low density lipoprotein; LDL) are observed in clinical pancreatitis $[15,27]$, increase of TG are not observed in these experimentally induced pancreatitis [4, 27]. Therefore, hyperlipidemia in acute pancreatitis might not be reproduced by ligation of pancreatic duct and infusion with mixture of bile and trypsin. In this study, induction of canine acute pancreatitis was attempted by the infusion with oleic acid (OA) into pancreatic duct.

Hyperlipidemia is brought by changes of lipoprotein metabolism. Apolipoproteins are structural proteins and participate in lipoprotein metabolism. Changes of apolipoprotein composition bring about abnormality in lipoprotein metabolism. Analysis of apolipoprotein is important to understand the changes of lipoprotein metabolism; however, there is no report on serum apolipoprotein profile in canine pancreatitis. The purpose of this study is to examine the effects of acute pancreatitis induced with $\mathrm{OA}$ on serum lipid and lipoprotein concentrations and apolipoprotein profile in dogs.

\section{MATERIALS AND METHODS}

Experimental animals: Eight male beagle dogs, weighing 10.5 to $14.5 \mathrm{~kg}$ and aged over one year were used. These dogs were divided into two groups. OA-treated dogs were injected with OA (Sigma Chemical Co., U.S.A.) and control dogs were injected with physiological saline (PS; Otsuka Seiyaku Co., Ltd., Tokyo).

Surgical manipulation and inducing pancreatitis: Operative procedures were performed on the dogs after premedication with atropine sulfate (Tanabe Seiyaku Co., Ltd., Osaka) and xylazine hydrochloride (Bayer Japan Co., Ltd., Tokyo) and induction with sodium thiamylal (Yoshitomi Seiyaku Co., Ltd., Osaka) and under inhalation anesthesia with isoflurane (Dainabot Co., Ltd., Tokyo). Laparotomy through a midline approach and duodenotomy was done. A flexible 22-gauge needle was inserted via the 
minor duodenal papilla into the accessory pancreatic duct and retained in the position by a ligation around the duct and needle. OA or PS was infused slowly into the accessory pancreatic duct at a volume of $0.5 \mathrm{ml} / \mathrm{kg}$ of body weight (BW). Three minutes after the infusion, the ligation and needle were removed from pancreatic duct and the incision of duodenum was closed by continuous suture.

Postoperative managements: The fluids were administered intravenously at a rate of $50 \mathrm{ml} / \mathrm{kg} \mathrm{BW} /$ day. In the dogs with vomiting and/or diarrhea, the additional amounts of fluids required to replace losses and to manage shock were given. The composition of the fluids was $10 \%$ of glucose, $0.1 \%$ of sodium lactate, $0.2 \%$ of sodium chloride $(\mathrm{NaCl}), 0.01 \%$ of potassium chloride and $0.005 \%$ of calcium chloride. Five days after the operation, all fluids were given orally ad libitum. The only other treatment given to all dogs was an intramuscular injection of ampicillin $(30 \mathrm{mg} /$ $\mathrm{kg} \mathrm{BW}$, twice a day). All dogs were not fed during 7 days after the operation. The dogs were necropsied at 7 th day.

Physical examinations and collection of samples: The frequency of diarrhea and vomiting, rectal temperature, pulse rate and respiratory rate were recorded and abdominal palpations were done before and 3, 8, 16, 24, 32, 40, 48, 72, 96, 120 and $144 \mathrm{hr}$ after the operation. Blood samples for serum amylase, lipase, C-reactive protein (CRP), lipid, and lipoprotein analysis were collected from jugular vein at the same time. The samples for hematological and biochemical examinations and apolipoprotein analysis were collected before and 24, 72 and $144 \mathrm{hr}$ after the operation.

Hematological and biochemical examinations: Hematological values were measured by Particle counter (Model PC-608, Erma Inc., Tokyo). Plasma biochemical examinations including the measurements of aspartate aminotransferase (AST), alanine aminotransferase (ALT), alkaline phosphatase (ALP) and total bilirubin (T. Bil) were performed by COBAS READY ${ }^{\circledR}$ (Nippon Roche, Tokyo). Amylase and lipase were determined by Amylase-test kit (Wako Pure Chemical Industries, Ltd., Osaka) and Lipase Kit S (Dainippon Seiyaku Co., Ltd., Osaka), respectively. CRP was measured by the method of laser nephelometric immunoassay using anti-canine CRP serum.

Serum lipid and lipoprotein analysis: Serum concentrations of TG, total cholesterol (TC), phospholipid (PL), total lipids (TL), non-esterified fatty acid (NEFA), and lipoprotein were determined by the method reported previously [7].

Preparation of lipoprotein fractions: Fractionation of the plasma lipoproteins into various density classes was accomplished by adding $\mathrm{NaCl}$ and potassium bromide $(\mathrm{KBr})$ to the plasma and centrifugation in a Hitachi CS120 ultracentrifuge (Hitachi Co., Ltd., Tokyo) with an angle rotor (Model RP120AT, Hitachi Co., Ltd., Tokyo) according to the procedure described by Bronzert and Brewer [6]. On $0.75 \mathrm{~m} l$ of plasma, $0.25 \mathrm{~m} l$ of $0.15 \mathrm{M} \mathrm{NaCl}$ and $0.3 \mathrm{mM}$ EDTA-2Na solution ( $\mathrm{pH} 7.4)$ was overlaid. After centrifugation at $120,000 \mathrm{rpm}(480,000 \times \mathrm{g})$ for $5 \mathrm{~min}$ at $10^{\circ} \mathrm{C}, 0.20 \mathrm{~m} l$ of the upper layer was separated as chylomicron $(\mathrm{CM}, \mathrm{d}<1.006 \mathrm{~g} / \mathrm{m} l)$ fraction and $0.75 \mathrm{~m} l$ of the bottom layer was removed into a new tube. On the removed sample, $0.25 \mathrm{~m} l$ of $0.15 \mathrm{M} \mathrm{NaCl}$ and $0.3 \mathrm{mM}$ EDTA-2Na solution was overlaid. After centrifugation at $120,000 \mathrm{rpm}$ for $2 \mathrm{hr}$ at $10^{\circ} \mathrm{C}, 0.20 \mathrm{ml}$ of the upper layer was separated as very low density lipoprotein (VLDL, $\mathrm{d}<1.006 \mathrm{~g} / \mathrm{ml}$ ) fraction and $0.75 \mathrm{ml}$ of the bottom layer was removed to another tube. Into the removed sample, 62.6 $\mathrm{mg}$ of $\mathrm{KBr}$ was dissolved. After centrifugation at 120,000 $\mathrm{rpm}$ for $2 \mathrm{hr}$ at $10^{\circ} \mathrm{C}, 0.20 \mathrm{ml}$ of the upper layer was separated as low density lipoprotein (LDL, $1.006<\mathrm{d}<1.063$ $\mathrm{g} / \mathrm{m} l$ ) fraction and $0.50 \mathrm{~m} l$ of the bottom layer was transferred into another tube. Into the transferred sample, $121.6 \mathrm{mg}$ of $\mathrm{KBr}$ was dissolved. After centrifugation at $120,000 \mathrm{rpm}$ for $3 \mathrm{hr}$ at $10^{\circ} \mathrm{C}, 0.20 \mathrm{ml}$ of the upper layer was separated as high density lipoprotein (HDL, $1.063<\mathrm{d}<1.210 \mathrm{~g} / \mathrm{m} l$ ) fraction and the bottom was separated as very high density lipoprotein (VHDL, d $>1.210 \mathrm{~g} / \mathrm{m} l$ ) fraction. LDL, HDL and VHDL fractions were dialyzed with PS. Protein concentration of each fraction was measured by the method of Bradford [5] and adjusted to $1,200-2,400 \mu \mathrm{g} / \mathrm{m} l$ by the dilution with PS or by concentration using Microcon ${ }^{\circledR}$ (Amicon Inc., MA).

Apolipoprotein analysis: Apolipoprotein profile of each lipoprotein fraction was analyzed with sodium dodecyl sulfate-polyacrylamide gel electrophoresis (SDS-PAGE) system (Model AE-6400, Atto Co., Tokyo). The lipoprotein samples were mixed with five times volume of $40 \mathrm{mM}$ Tris$\mathrm{HCl}$ buffer (pH 6.8) containing 3.5\% (W/V) SDS, $14 \%$ (V/ $\mathrm{V})$ glycerol and $200 \mathrm{mM}$ dithiothreitol and were heated at $95^{\circ} \mathrm{C}$ for $5 \mathrm{~min}$. SDS-PAGE was performed in a slab gel gradient (5-20\%; PAGEL ${ }^{\circledR}$, Atto Co., Tokyo) with electrophoresis buffer ( $\mathrm{pH} 8.3$ ) containing $0.1 \%$ (W/V) SDS, $25 \mathrm{mM}$ Tris and $195 \mathrm{mM}$ glycine for $60 \mathrm{~min}$ at $25 \mathrm{~mA}$. Proteins were stained with coomassie brilliant blue R-250. The distribution patterns of apolipoprotein were determined in a Densito-Pattern Analyzer (Model EPA-3000, Maruzen Petrochemical Co., Ltd., Tokyo) at wavelength of $650 \mathrm{~nm}$.

Immuno-blotting electrophoresis: Apolipoprotein in HDL fraction was subjected to SDS-PAGE as described above. Transcription into nitrocellulose sheet was accomplished according to the method described by Towbin et al. [26]. Immuno-blotting electrophoretic blots were soaked in Block Ace (Dainippon Seiyaku Co., Ltd., Osaka) for $30 \mathrm{~min}$ at $37^{\circ} \mathrm{C}$. They were rinsed with phosphate buffered saline (PBS) contained $0.05 \%(\mathrm{~V} / \mathrm{V})$ polyoxyethylene sorbitan monolaurate (Wako Pure Chemical Industries Ltd., Osaka; Tween-PBS) and PBS, and incubated with rabbit anti-canine serum amyloid A protein (SAA) serum (kindly provided by Dr. T. Kajikawa, Department of Veterinary Microbiology) for $1 \mathrm{hr}$ at room temperature. The blots were rinsed with Tween-PBS and PBS and incubated with biotin-labeled antirabbit IgG (Vector Laboratories, Inc., U.S.A.) for $30 \mathrm{~min}$ at room temperature. They were washed with Tween-PBS and PBS and incubated with avidin:biotinylated peroxidase complex (Vector Laboratories, Inc., U.S.A.) for $30 \mathrm{~min}$ at room temperature. The electrophoretic blots were washed 
with Tween-PBS and PBS and peroxidase activities were detected with PBS containing 0.06\% (W/V) 4-chloro-1naphthol, $4.7 \%(\mathrm{~V} / \mathrm{V})$ methanol and $0.01 \%(\mathrm{~V} / \mathrm{V})$ hydrogen peroxide.

Pathological examinations: After the necropsy, pancreas was removed, fixed in $10 \%$ neutral buffered formalin solution, paraffin-embedded, cut in $5 \mu \mathrm{m}$ sections and stained with Hematoxylin-Eosin.

Statistical analysis: Differences between pre- and postoperative values and two groups were analyzed by paired and Student's $t$-test, respectively. When variances were unequal, Cochran-Cox's test was used.

\section{RESULTS}

Physical examinations: In OA-treated dogs, all dogs were depressed and swelling of pancreas was detected by abdominal palpation during the experimental period. The mean times (range) of vomiting and diarrhea in OA-treated dogs during the seven days were 12.3 (7-22) and 5.5 (1$10)$, respectively. Mean temperature in OA-treated dogs was significantly $(\mathrm{p}<0.05)$ higher than that in control dogs after $96 \mathrm{hr}$. Pulse rates in OA-treated dogs were significantly $(\mathrm{p}<0.05)$ higher than in control dogs, however respiration rates did not change during the study period (data not shown). There were no changes in physical examination except vomiting in control dogs.

Hematological examinations: Hematological values of two groups are presented in Table 1. White blood cell count (WBC) of OA-treated dogs were not significantly different from the preoperative value. Hematocrit of OAtreated dogs significantly $(\mathrm{p}<0.05)$ increased at $24 \mathrm{hr}$ after the operation but this increase was temporary. WBC in OA-treated dogs at $144 \mathrm{hr}$ significantly $(\mathrm{p}<0.05)$ lower and hematocrit at $24 \mathrm{hr}$ significantly $(\mathrm{p}<0.01)$ higher than those in control dogs. Moreover, blood samples of OA-treated dogs showed hemolysis from 3 to $72 \mathrm{hr}$ and jaundice from 16 to $144 \mathrm{hr}$ after the operation. Hematological values in control dogs were not significantly different from the preoperative values.

Biochemical examinations: Mean activities of AST and ALT in OA-treated dogs at $24 \mathrm{hr}$ after the operation were significantly $(\mathrm{p}<0.05)$ higher than the preoperative activities. These values decreased to the preoperative values after 72 hr but were significantly $(\mathrm{p}<0.05)$ higher than those in control dogs. ALP activity and T. Bil concentration in OAtreated dogs at $24 \mathrm{hr}$ were significantly $(\mathrm{p}<0.01$ and $\mathrm{p}<0.05$, respectively) greater than the preoperative values and these tended to increase until $144 \mathrm{hr}$. Serum amylase activities immediately increased after the injection with $\mathrm{OA}$ and reached a maximum at $8 \mathrm{hr}\left(1.55 \pm 0.63 \times 10^{4} \mathrm{~S}-\mathrm{RU}\right)$. These activities gradually decreased but were still significantly $(\mathrm{p}<0.05)$ greater than the preoperative value and those in control dogs. Serum lipase activities in OAtreated dogs increased and peaked at $16 \mathrm{hr}(1.27 \pm 0.30 \times$ $\left.10^{3} \mathrm{IU} / l\right)$. These activities gradually decreased but the values from 8 through $48 \mathrm{hr}$ were significantly $(\mathrm{p}<0.05)$ higher than those in control dogs. Lipase activities in control dogs from 32 through $144 \mathrm{hr}$ were significantly $(p<0.05)$ decreased. Mean concentrations of CRP in two

Table 1. Hematological and biochemical values in dogs

\begin{tabular}{|c|c|c|c|c|c|}
\hline \multirow{2}{*}{\multicolumn{2}{|c|}{ Examination }} & \multicolumn{4}{|c|}{ Time after injection (hour) } \\
\hline & & 0 & 24 & 72 & 144 \\
\hline \multicolumn{6}{|c|}{ OA-treated dogs } \\
\hline WBC & $\times 10^{2} / \mathrm{mm}^{3}$ & $147 \pm 59^{\mathrm{a})}$ & $148 \pm 42$ & $157 \pm 33$ & $110 \pm 42^{\dagger c}$ \\
\hline Hematocrit & $\%$ & $45.4 \pm 4.9$ & $64.8 \pm 7.2 * * \dagger \dagger$ & $42.8 \pm 9.6$ & $44.2 \pm 5.4$ \\
\hline AST & $\mathrm{IU} / l$ & $25 \pm 7$ & $159 \pm 70 * \dagger$ & $51 \pm 26$ & $20 \pm 3^{\dagger \dagger}$ \\
\hline ALT & $\mathrm{IU} / l$ & $62 \pm 27$ & $184 \pm 50 * \mathrm{~b})$ & $132 \pm 60^{\dagger}$ & $45 \pm 17^{\dagger}$ \\
\hline ALP & $\mathrm{IU} / l$ & $63 \pm 15$ & $190 \pm 28 * *$ & $268 \pm 91 * \dagger$ & $359 \pm 281$ \\
\hline T. Bil & $\mathrm{mg} / \mathrm{d} l$ & $0.3 \pm 0.0$ & $0.6 \pm 0.1$ *† $\dagger$ & $0.7 \pm 0.3$ & $0.6 \pm 0.3$ \\
\hline Amylase & $\times 10^{3} \mathrm{~S}-\mathrm{RU}$ & $0.66 \pm 0.32$ & $12.1 \pm 3.42 * \dagger$ & $5.50 \pm 1.21 * * \dagger \dagger \dagger$ & $1.96 \pm 0.36 * \dagger \dagger$ \\
\hline Lipase & $\times 10^{3} \mathrm{IU} / \mathrm{l}$ & $0.75 \pm 0.17$ & $1.20 \pm 0.31 *$ & $0.52 \pm 0.07$ & $0.28 \pm 0.03^{*}$ \\
\hline CRP & $\mathrm{mg} / \mathrm{d} l$ & $0.30 \pm 0.0$ & $25.0 \pm 6.1 * * \dagger$ & $27.5 \pm 5.0 * * \dagger \dagger$ & $25.0 \pm 3.3 * * * \dagger$ \\
\hline \multicolumn{6}{|l|}{ Control dogs } \\
\hline WBC & $\times 10^{2} / \mathrm{mm}^{3}$ & $143 \pm 51$ & $196 \pm 31$ & $162 \pm 26$ & $213 \pm 51$ \\
\hline Hematocrit & $\%$ & $44.6 \pm 3.8$ & $46.6 \pm 3.8$ & $42.6 \pm 3.5$ & $41.2 \pm 2.3$ \\
\hline AST & $\mathrm{IU} / l$ & $15 \pm 6$ & $14 \pm 2$ & $13 \pm 3$ & $12 \pm 2$ \\
\hline ALT & $\mathrm{IU} / l$ & $22 \pm 7$ & $44 \pm 14$ & $29 \pm 12$ & $22 \pm 8$ \\
\hline ALP & $\mathrm{IU} / l$ & $59 \pm 11$ & $83 \pm 28$ & $67 \pm 18$ & $61 \pm 11$ \\
\hline T. Bil & $\mathrm{mg} / \mathrm{d} l$ & $0.3 \pm 0.0$ & $0.3 \pm 0.1$ & $0.3 \pm 0.0$ & $0.3 \pm 0.1$ \\
\hline Amylase & $\times 10^{3} \mathrm{~S}-\mathrm{RU}$ & $0.77 \pm 0.11$ & $2.49 \pm 1.26$ & $0.95 \pm 0.43$ & $0.86 \pm 0.40$ \\
\hline Lipase & $\times 10^{3} \mathrm{IU} / l$ & $0.92 \pm 0.30$ & $0.62 \pm 0.15$ & $0.43 \pm 0.10^{*}$ & $0.32 \pm 0.08^{*}$ \\
\hline CRP & $\mathrm{mg} / \mathrm{d} l$ & $0.3 \pm 0.0$ & $9.9 \pm 1.7 * *$ & $9.3 \pm 5.1^{*}$ & $14.0 \pm 7.3$ \\
\hline
\end{tabular}

WBC: white blood cell count, RBC: red blood cell count, AST:aspartate aminotransferase, ALT: alanine aminotransferase, ALP: alkaline phosphatase, T. Bil: total bilirubin, BUN: blood urea nitrogen, CRP: C-reactive protein. a) Mean \pm Standard deviation (S.D.). b) Significantly different from preoperative value. *: $\mathrm{p}<0.05$, **: $\mathrm{p}<0.01, * * *: \mathrm{p}<0.001$. c) Significantly different from control dogs. ${ }^{\dagger}: \mathrm{p}<0.05,{ }^{\dagger}{ }^{\dagger}: \mathrm{p}<0.01,{ }^{\dagger}{ }^{\dagger} \mathrm{t}: \mathrm{p}<0.001$. 


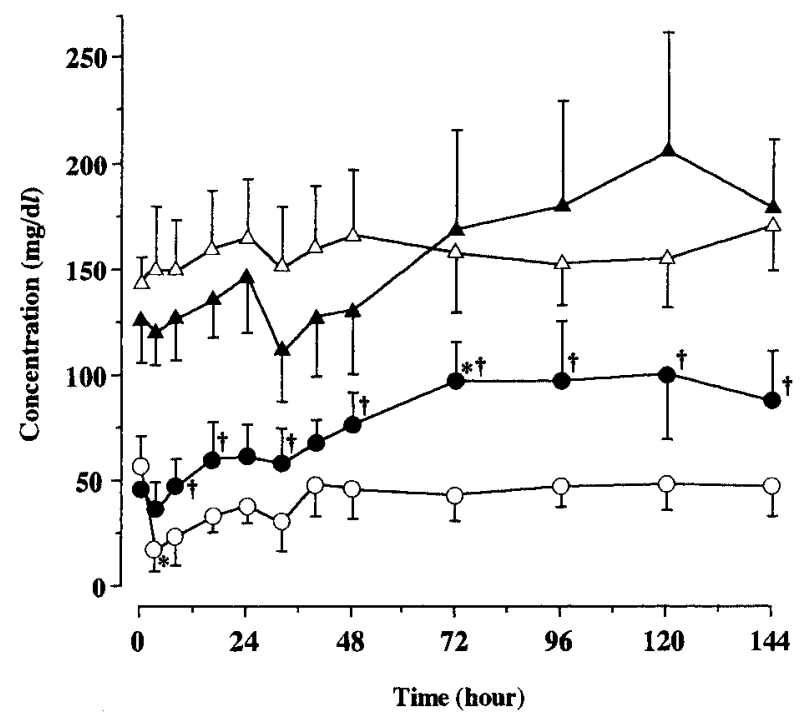

Fig. 1. Serum triglyceride concentrations in oleic acid-treated dogs (O) and control $\operatorname{dogs}(\bigcirc)$, and total cholesterol concentrations in oleic acid-treated $\operatorname{dogs}(\boldsymbol{\Delta})$ and control $\operatorname{dogs}(\triangle)$ after the operation. Vertical bars show standard error. *: Significantly $(\mathrm{p}<0.05)$ different from preoperative value. $†$ : Significantly $(\mathrm{p}<0.05)$ different from control dogs.

groups significantly $(\mathrm{p}<0.05)$ increased after $8 \mathrm{hr}$; moreover, CRP concentrations in OA-treated dogs were significantly $(\mathrm{p}<0.05)$ higher than those in control dogs from 16 through $144 \mathrm{hr}$. Mean activities of AST, ALT, ALP and amylase and concentration of $\mathrm{T}$. Bil in control dogs were not significantly different from the preoperative values (Table 1).

Pathological examination: At necropsy, the left lobe of pancreas from OA-treated dogs showed swelling and petechial hemorrhage. Histopathologic findings were included the degeneration and necrosis of pancreatic acinar cell accompanied with fibrosis and hemorrhage. Pancreata from control dogs were normal in pathological examination. These changes confirmed that the infusion with OA induced acute pancreatitis.

Lipid concentrations: Serum TG concentrations in OAtreated dogs gradually increased and were significantly $(\mathrm{p}<0.05)$ higher than those in control dogs from 48 through $144 \mathrm{hr}$, whereas those in control dogs were significantly $(\mathrm{p}<0.05)$ lower than the preoperative value at $3 \mathrm{hr}$ and returned to the preoperative value (Fig. 1). Two groups of dogs showed no major changes in serum TC (Fig. 1) and PL (Fig. 2) concentrations after the operation. Serum NEFA concentrations in OA-treated dogs decreased at $3 \mathrm{hr}$ and increased until $16 \mathrm{hr}$, however they returned to the preoperative level after $32 \mathrm{hr}$. The changes of serum NEFA concentrations in control dogs resembled those in OAtreated dogs until $32 \mathrm{hr}$ but significantly $(\mathrm{p}<0.05)$ increased after $40 \mathrm{hr}$. These concentration at 48 and $72 \mathrm{hr}$ were significantly $(\mathrm{p}<0.05)$ higher than those in OA-treated dogs (Fig. 2).

Lipoprotein concentrations: Serum TG concentrations in

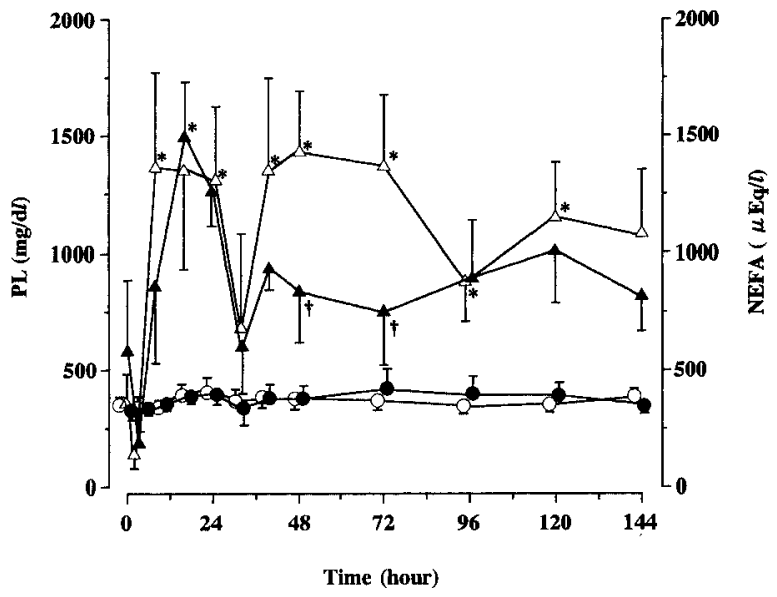

Fig. 2. Serum phospholipid concentrations in oleic acid-treated dogs $(\bigcirc)$ and control dogs $(\bigcirc)$, and non-esterified fatty acid concentrations in oleic acid-treated dogs $(\boldsymbol{\Delta})$ and control dogs $(\triangle)$ after the operation. Vertical bars show standard error. *: Significantly $(\mathrm{p}<0.05)$ different from preoperative value. $\dagger$ : Significantly $(\mathrm{p}<0.05)$ different from control dogs.

beta lipoprotein in OA-treated dogs after $72 \mathrm{hr}$ significantly $(p<0.05)$ higher than those in control dogs (Fig. 3). Serum TG concentrations in control dogs significantly $(\mathrm{p}<0.05)$ decreased at $3 \mathrm{hr}$ after the operation (Fig. 3B). Two groups of dogs showed no major changes in serum TG concentrations in origin, pre-beta and alpha ${ }_{1}$ lipoprotein after the operation. The changes of serum TC (Fig. 4), PL (Fig. 5) and TL (data not shown) concentrations in each lipoprotein resembled each other. In OA-treated dogs, these lipid concentrations in beta and pre-beta lipoprotein increased and those in alpha ${ }_{1}$ lipoprotein decreased after 24-40 hr (Figs. 4A and 5A). Moreover, these values were significantly $(\mathrm{p}<0.05)$ different from those in control dogs. In control dogs, these lipids in beta lipoprotein significantly $(\mathrm{p}<0.05)$ decreased until $8 \mathrm{hr}$, however there were no significant changes in other lipoproteins after the injection of PS (Figs. 4B and 5B).

Apolipoprotein distributions: The typical electropherogram of apolipoprotein distributions in lipoprotein fractions is shown in Fig. 6. Canine lipoproteins consisted of five major apolipoproteins including apolipoprotein B100 (apo B100), apolipoprotein B48 (apo B48), apolipoprotein A-IV (apo A-IV), apolipoprotein E (apo E) and apolipoprotein A-I (apo A-I). Apolipoprotein distributions and total concentrations in VLDL, LDL and HDL fractions are shown in Table 2. The CM and VHDL fractions were excepted from apolipoprotein profile analysis because of insufficient $\mathrm{CM}$ separation and contamination of VHDL with other serum proteins. VLDL fraction contained two major apolipoproteins, apo B100 and apo B48. Apo B100 and apo A-I constituted LDL fraction and apo A-IV and apo A-I were major apolipoproteins of HDL fraction. Apolipoprotein compositions and total concentrations of each lipoprotein fraction in control dogs did not changed 

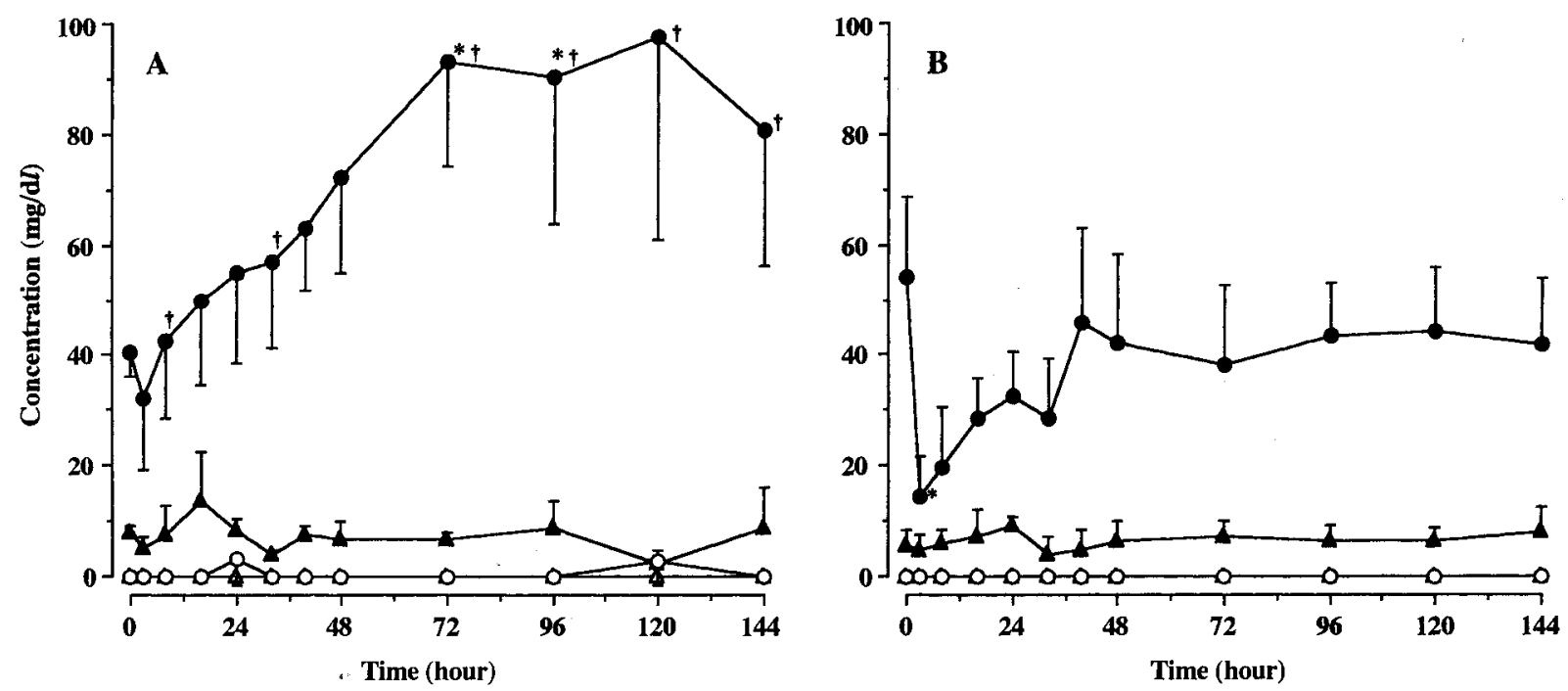

Fig. 3. Serum triglyceride concentrations in origin $(\triangle)$, pre- $\beta$ lipoprotein $(\boldsymbol{\Delta}), \beta$ lipoprotein $(\boldsymbol{O})$ and $\alpha_{1}$ lipoprotein $(\bigcirc)$ from oleic acid-treated (A) and control (B) dogs. Vertical bars show standard error. *: Significantly $(\mathrm{p}<0.05)$ different from preoperative value. $\dagger$ : Significantly $(\mathrm{p}<0.05)$ different from control dogs.
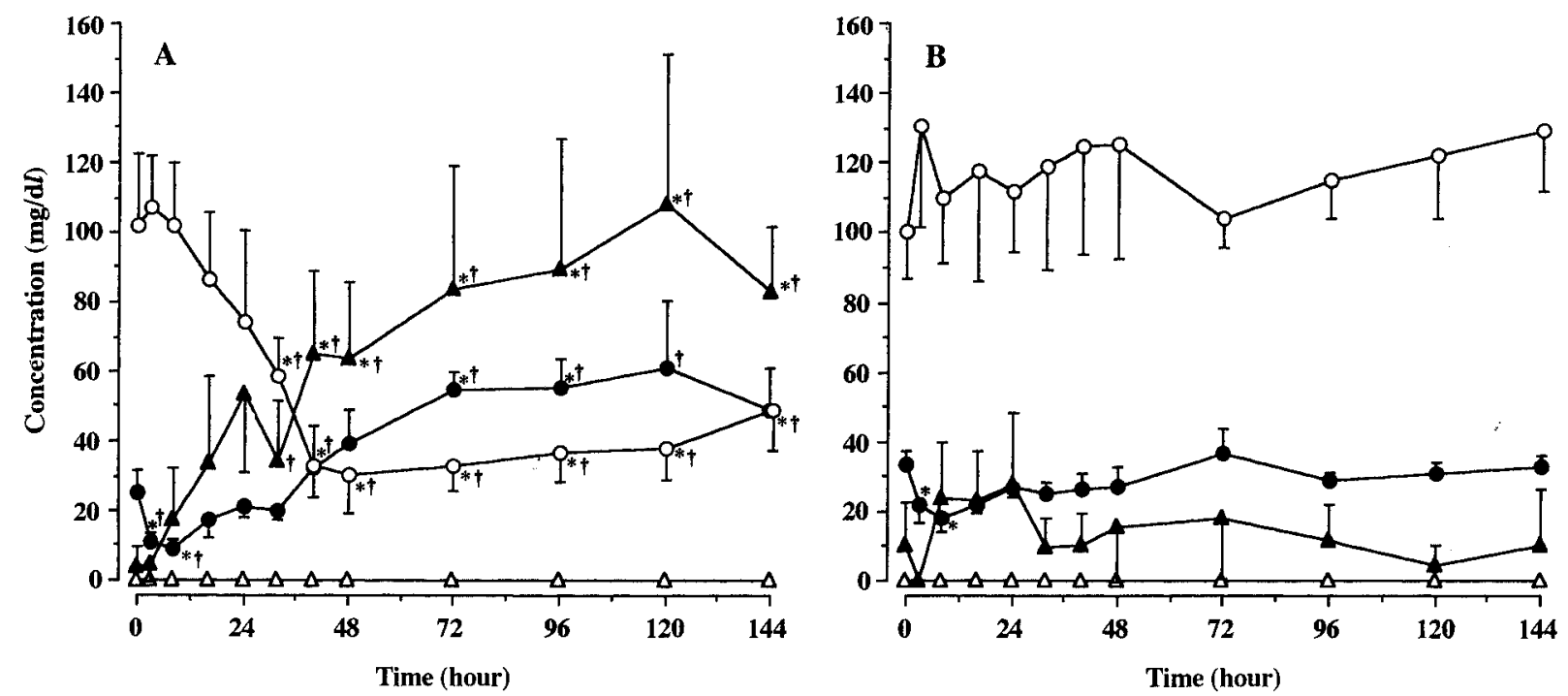

Fig. 4. Serum total cholesterol concentrations in origin $(\triangle)$, pre- $\beta$ lipoprotein $(\boldsymbol{\Delta}), \beta$ lipoprotein $(\boldsymbol{O})$ and $\alpha_{1}$ lipoprotein $(\bigcirc)$ from oleic acid-treated (A) and control (B) dogs. Vertical bars show standard error. *: Significantly $(\mathrm{p}<0.05)$ different from preoperative value. $\dagger$ : Significantly $(\mathrm{p}<0.05)$ different from control dogs.

after the injection with PS. There were no significant differences of the apolipoprotein composition in VLDL fraction between before and after the injection with OA. However, the proportions of apo B100 in LDL fraction and apo A-IV in HDL fraction significantly $(\mathrm{p}<0.05)$ increased after $144 \mathrm{hr}$ and $72 \mathrm{hr}$, respectively, and apo A-I in HDL fraction significantly $(\mathrm{p}<0.05)$ decreased after $24 \mathrm{hr}$. Furthermore, $13 \mathrm{kDa}$ apolipoprotein appeared in HDL fraction after the injection with OA. Canine apolipoprotein concentrations in VLDL were less than detectable limit (1.7 $\mu \mathrm{g} / \mathrm{m} l)$. Total apolipoprotein concentrations in LDL significantly $(\mathrm{p}<0.05)$ increased and those in HDL tended to decrease after the injection with OA (Table 2).
Immuno-blotting electrophoresis: SDS-polyacrylamide gel and immuno-blotting electropherogram in HDL fraction are shown in Fig. 7. The $13 \mathrm{kDa}$ protein was strongly reacted with anti-SAA serum.

\section{DISCUSSION}

Acute pancreatitis has been experimentally induced in dogs by a wide variety of means for example the ligation of the pancreatic duct [15] and the injection with bile and trypsin into the pancreatic duct [27]. The occurrence of obstruction of pancreatic duct is rare in dogs [17]. Attix et al. [2] reported that the infusion of fatty acids into the 

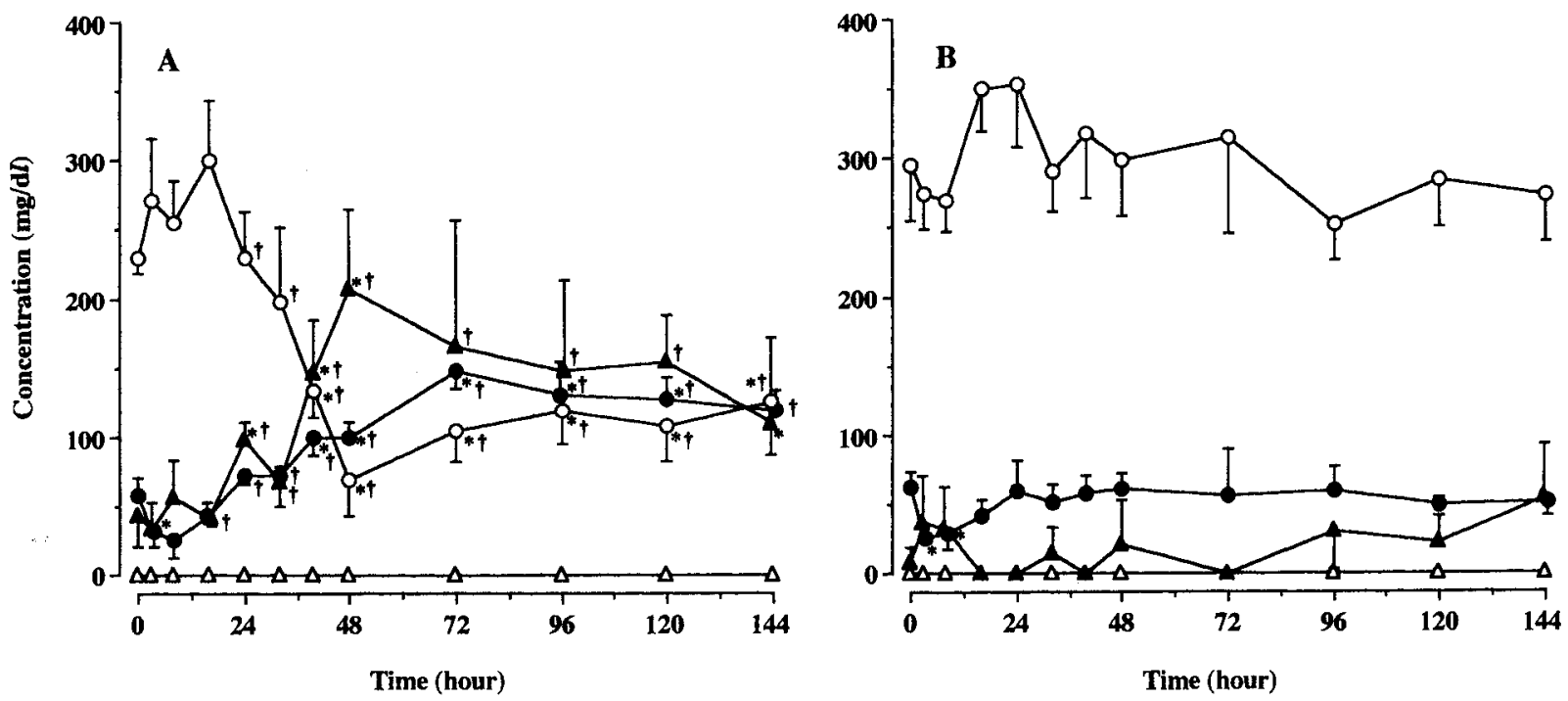

Fig. 5. Serum phospholipid concentrations in origin $(\triangle)$, pre- $\beta$ lipoprotein $(\boldsymbol{\Delta}), \beta$ lipoprotein $(\boldsymbol{O})$ and $\alpha_{1}$ lipoprotein $(\bigcirc)$ from oleic acid-treated (A) and control (B) dogs. Vertical bars show standard error. *: Significantly $(\mathrm{p}<0.05)$ different from preoperative value. $\dagger$ : Significantly $(\mathrm{p}<0.05)$ different from control dogs.

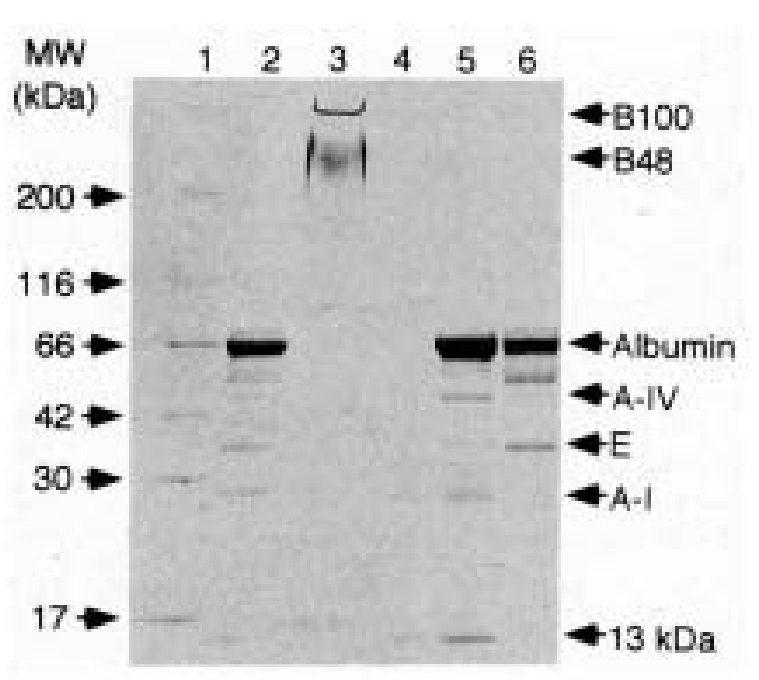

Fig. 6. Apolipoprotein distributions in oleic acid-treated dogs. Lane 1, molucular weight markers; lane 2, chylomicron fraction; lane 3, very low density lipoprotein fraction; lane 4, low density lipoprotein fraction; lane 5, high density lipoprotein fraction; lane 6 , very high density lipoprotein fraction. Apolipoprotein distributions in control dogs were resembled to this result except the appearance of 13 $\mathrm{kDa}$ protein.

pancreatic duct mimics what may occur with reflux of duodenal contents following consumption of a high-fat diet. In this study, induction of canine acute pancreatitis was attempted by the infusion with oleic acid according to their mean.

OA-treated dogs showed depression, swelling of pancreas, vomiting, diarrhea, hyperthermia and tachycardia.

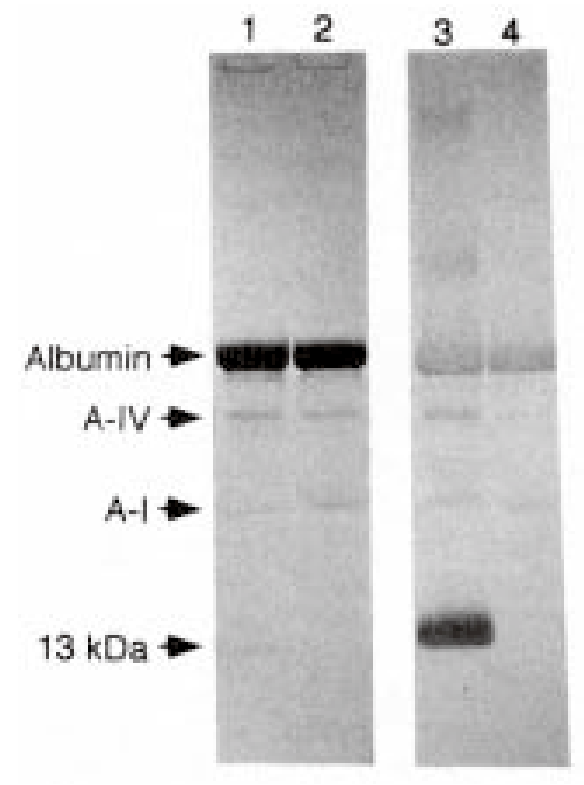

Fig. 7. Protein-stained SDS-polyacrylamide gel (SDS-PAGE) patterns and anti-SAA immuno-blotting electropherograms in high density lipoprotein fraction. Lane 1, SDS-PAGE in oleic acid-treated dog; lane 2, SDS-PAGE in control dog; lane 3, immuno-blotting in oleic acid-treated dog; lane 4, immuno-blotting in control dog.

Hemoconcentration and increased activities of amylase and lipase and increased concentration of CRP were also observed in OA-treated dogs. Furthermore, the degeneration and necrosis of pancreatic acinar cell accompanied with fibrosis and hemorrhage were observed in pathological 
Table 2. Apolipoprotein distributions and total concentrations of lipoprotein fractions in oleic acid-treated dogs and control dogs

\begin{tabular}{|c|c|c|c|c|c|}
\hline \multirow{2}{*}{\multicolumn{2}{|c|}{$\begin{array}{l}\text { Fraction/ } \\
\text { Apolipoprotein }\end{array}$}} & \multicolumn{4}{|c|}{ Time after injection (hour) } \\
\hline & & 0 & 24 & 72 & 144 \\
\hline \multicolumn{6}{|c|}{ OA-treated dogs } \\
\hline \multicolumn{6}{|c|}{ VLDL } \\
\hline apo B100 & $\%$ & $59.7 \pm 19.8^{\mathrm{a})}$ & $62.3 \pm 35.6$ & $39.5 \pm 22.1$ & $37.0 \pm 13.8$ \\
\hline apo B48 & $\%$ & $40.4 \pm 19.8$ & $37.7 \pm 35.6$ & $50.1 \pm 14.4$ & $63.0 \pm 13.8$ \\
\hline others & $\%$ & - & - & $10.4 \pm 12.6$ & - \\
\hline total conce & ntration $\mu \mathrm{g} / \mathrm{m} l$ & 1.d. b) $^{2}$ & 1.d. & 1.d. & 1.d. \\
\hline \multicolumn{6}{|c|}{ LDL } \\
\hline apo B100 & $\%$ & $29.3 \pm 19.5$ & $50.2 \pm 5.8$ & $35.7 \pm 7.6$ & $88.0 \pm 17.4^{* c)}$ \\
\hline apo A-I & $\%$ & $40.3 \pm 24.6$ & $47.3 \pm 5.6$ & $48.1 \pm 13.0$ & $12.0 \pm 17.4$ \\
\hline others & $\%$ & $30.4 \pm 23.1$ & $2.5 \pm 4.4$ & $16.2 \pm 16.2$ & - \\
\hline total conce & ntration $\mu \mathrm{g} / \mathrm{m} l$ & $68 \pm 34$ & $195 \pm 67$ & $259 \pm 37 * * * \dagger \mathrm{d})$ & $266 \pm 7 * *$ \\
\hline \multicolumn{6}{|c|}{$\mathrm{HDL}$} \\
\hline apo A-IV & $\%$ & $10.5 \pm 9.7$ & $22.6 \pm 6.6$ & $23.4 \pm 10.3^{*}$ & $43.4 \pm 8.7 *$ \\
\hline apo A-I & $\%$ & $89.5 \pm 9.7$ & $60.6 \pm 9.9 * *$ & $50.6 \pm 9.4 * *$ & $49.2 \pm 4.0^{*}$ \\
\hline $13 \mathrm{kDa}$ & $\%$ & - & $16.9 \pm 3.9 * * \dagger \dagger$ & $26.0 \pm 3.4 * * * \dagger \dagger$ & $7.5 \pm 4.7$ \\
\hline total conce & ntration $\times 10^{3} \mu \mathrm{g} / \mathrm{m} l$ & $1.80 \pm 0.38$ & $1.51 \pm 0.46$ & $1.22 \pm 0.71$ & $1.16 \pm 0.23$ \\
\hline \multicolumn{6}{|c|}{ Control dogs } \\
\hline \multicolumn{6}{|l|}{ VLDL } \\
\hline apo B100 & $\%$ & $42.7 \pm 43.9$ & $45.0 \pm 35.8$ & $50.8 \pm 16.0$ & $63.1 \pm 14.3$ \\
\hline apo B48 & $\%$ & $45.0 \pm 36.5$ & $55.0 \pm 35.8$ & $49.2 \pm 16.0$ & $36.9 \pm 14.3$ \\
\hline others & $\%$ & $12.3 \pm 21.3$ & - & - & - \\
\hline total conce & ntration $\mu \mathrm{g} / \mathrm{m} l$ & 1.d. & 1.d. & 1.d. & 1.d. \\
\hline \multicolumn{6}{|c|}{ LDL } \\
\hline apo B100 & $\%$ & $63.6 \pm 21.5$ & $63.5 \pm 10.5$ & $62.4 \pm 11.8$ & $68.0 \pm 11.3$ \\
\hline apo A-I & $\%$ & $36.5 \pm 21.5$ & $36.5 \pm 10.5$ & $37.6 \pm 11.8$ & $32.0 \pm 11.3$ \\
\hline others & $\%$ & - & - & - & - \\
\hline total conce & ntration $\mu \mathrm{g} / \mathrm{m} l$ & $63 \pm 18$ & $200 \pm 76$ & $158 \pm 41$ & $224 \pm 98$ \\
\hline \multicolumn{6}{|c|}{ HDL } \\
\hline apo A-IV & $\%$ & $17.5 \pm 10.4$ & $37.8 \pm 14.3$ & $35.5 \pm 11.0$ & $34.1 \pm 10.4$ \\
\hline apo A-I & $\%$ & $82.5 \pm 10.4$ & $62.2 \pm 14.3$ & $64.5 \pm 11.0$ & $53.7 \pm 18.2$ \\
\hline $13 \mathrm{kDa}$ & $\%$ & - & - & - & $12.2 \pm 14.9$ \\
\hline total conce & ntration $\times 10^{3} \mu \mathrm{g} / \mathrm{m} l$ & $1.70 \pm 0.41$ & $1.55 \pm 0.63$ & $1.65 \pm 0.63$ & $1.80 \pm 0.43$ \\
\hline
\end{tabular}

VLDL: Very low density lipoprotein, LDL: Low density lipoprotein, HDL: High density lipoprotein. a) Mean \pm S.D. b) Less than detectable limit. c) Significantly different from preoperative value. $*$ : $p<0.05, * *$ : $p<0.01, * * *$ : $<<0.001$. d) Significantly different from control dogs. ${ }^{\dagger}: \mathrm{p}<0.05,{ }^{\dagger}{ }^{\dagger}: \mathrm{p}<0.01$.

examination. These results indicated that the infusion with OA into the pancreatic duct induced canine acute pancreatitis.

The temporary increase of AST and ALT activities in OA-treated dogs suggested that the disturbance of hepatocyte might occur after the infusion. The increased concentration of T. Bil and increased activity of ALP in OA-treated group might be attributed to the bile duct obstruction involved in tumefaction of pancreas.

Serum TC and PL concentrations were not influenced by OA-induced pancreatitis, but TG levels significantly increased from $48 \mathrm{hr}$ after the injection with OA. These results suggested that hyperlipidemia seen in canine acute pancreatitis was characterized by hypertriglyceridemia rather than hypercholesterolemia and supported the report that elevated cholesterol levels were not associated with pancreatitis [24]. Decreased TG concentrations from 3 to $32 \mathrm{hr}$ after the operation in control dogs were supposed to be the influence of anesthesia and/or operation. Decreased
NEFA concentrations in two groups at $3 \mathrm{hr}$ might be due to anesthesia [25] and increased concentration at $16 \mathrm{hr}$ might be associated with the influence of operation.

Increased serum TG concentration in OA-treated dogs was attributed to increased TG level in beta lipoprotein. Although serum total TC and PL concentrations were unchanged in OA-treated dogs, TC, PL and TL concentrations in beta and pre-beta lipoprotein increased and those in alpha ${ }_{1}$ lipoprotein decreased. Furthermore, total apolipoprotein concentrations in LDL fraction (beta lipoprotein) increased and those in HDL fraction (alpha lipoprotein) decreased after the injection with OA. These results suggested that canine acute pancreatitis induced with OA might increase quantity of beta (LDL) and pre-beta lipoprotein (VLDL) and decreased of alpha ${ }_{1}$ lipoprotein (HDL). These changes in serum lipoprotein and lipid levels were similar to other clinical reports [15, 27], however hypertriglyceridemia was not in accordance with other experimentally induced pancreatitis $[4,27]$. These might 
be derived from difference in the methods inducing pancreatitis and pancreatitis induced by infusion with OA approximates more closely to the naturally occurring disease.

Mahley and Weisgraber have proposed the density range of canine plasma lipoprotein [12]. In this study, lipoprotein fractions were isolated according to the human lipoprotein density. Therefore, there have been a possibility that LDL fraction may contain $\mathrm{HDL}_{1}$ and $\mathrm{HDL}$ fraction may contain $\mathrm{HDL}_{1}$ and small amount of LDL.

Apolipoprotein composition in each lipoprotein fraction was unchanged as well as the lipid concentration in each lipoprotein after the injection with PS. These results suggested that the lipid and lipoprotein concentrations and the apolipoprotein composition were not affected by the injection with PS. The proportion of apo B100 in LDL fraction increased after the injection with OA. Apo B100 is synthesized in the liver, secreted with VLDL and transferred into LDL in the process of VLDL metabolism. Apo B100 is a major factor for binding LDL to LDL receptor and catabolic process of LDL. The proportion of apo B100 in VLDL fraction was unchanged and that in LDL fraction increased in this study. These results suggested that the change of apolipoprotein composition in LDL occurred in the process of LDL synthesis and changed composition might bring about the increased quantity of LDL. Decreased proportion of apo A-I, increased proportion of apo A-IV and appearance of $13 \mathrm{kDa}$ protein in $\mathrm{HDL}$ fraction were observed after the injection with OA. Apo A-I is a major structural protein of HDL and an activator of lecithincholesterol acyltransferase. Decreased proportion of apo A-I depresses the function of HDL which is "reverse cholesterol transport" [22]. It is reported that serum apo A$\mathrm{I}$ is trapped by the pancreatic extracellular matrix and decreases in chronic calcifying pancreatitis [14]. Decreased proportion of apo A-I in this study might be due to the same reason. Markedly low apo A-IV levels have been observed in patients with chronic pancreatitis and the mechanism has been considered to be mainly due to the decrease in lipid absorption from the intestine [20], however increased proportion of apo A-IV in HDL was observed in this study. The most striking change in HDL fraction was the appearance of the $13 \mathrm{kDa}$ protein. This protein was identified as a SAA by an immunological method. SAA is one of the acute phase protein and HDL from patients in acute phases contains a large amount of SAA [23]. In control dogs, SAA was detected in HDL fraction after 144 $\mathrm{hr}$. This appearance might be attribute to response of healing of wound, but the details were unknown. It has been suggested that apo A-II may be replaced by increased amount of SAA and apo A-II concentration decrease in acute pancreatitis [19]. It is reported that SAA-rich HDL incubated with leukocyte is degraded rapidly [23]. Decreased quantity of HDL in this study might be attributed to accelerated degradation by SAA.

The mechanisms of hypertriglyceridemia is overproduction of pre-beta lipoprotein (VLDL) and apolipoprotein B and/or decreased clearance of origin and pre-beta (TG-rich) lipoprotein [8]. Increased TG and total apolipoprotein concentrations and changed apolipoprotein composition in beta lipoprotein (LDL) were observed in this study. Therefore, hypertriglyceridemia in beta lipoprotein might be caused by the decreased clearance of beta lipoprotein rather than the overproduction of pre-beta lipoprotein and apolipoprotein B. Serum concentrations of TC and PL were not changed, but these levels in lipoprotein were affected by pancreatitis. Increased TC and PL concentrations in beta and pre-beta lipoprotein might be applied to the mechanisms of hypertriglyceridemia [8]. Furthermore, decreased concentration of alpha ${ }_{1}$ was observed. This result might be caused by the accelerated degradation of alpha ${ }_{1}$ lipoprotein by the appearance of SAA rather than the depressed secretion from liver and intestine and the decreased catabolism of pre-beta to alpha lipoprotein [7]. Further studies on the lipoprotein metabolism, especially increased lipid concentrations in prebeta lipoprotein are needed.

Information on canine secondary hyperlipidemia is limited. Hypercholesterolemia with change of lipoprotein concentration has been reported in diabetes mellitus [3, 15], hyperadrenocorticism [3], hyperthyroidism [3, 15] and hepatic necrosis [4]. The changes of lipid and lipoprotein concentration in these reports were different from our results of experimentally induced pancreatitis. Therefore, the evaluation of serum lipid and lipoprotein concentration could be useful for diagnosis of canine acute pancreatitis in addition to amylase and lipase activities.

In obese dogs, hypertriglyceridemia, i.e. increased levels of beta and pre-beta lipoprotein and decreased level of alpha lipoprotein has been reported [7]. The same changes in serum lipid and lipoprotein concentrations were also observed in OA-treated dogs. There is a considerable amount of data to suggest that the hyperlipidemia seen in human subjects with acute pancreatitis precedes the onset of that disease. Although the mechanism remains unknown, it is speculated that high levels of triglyceride meet with increased concentrations of pancreatic lipase in the pancreatic capillaries, releasing large quantities of free fatty acids that exceed the albumin binding capacity. They are, therefore, free to induce toxic vascular injury and acute pancreatitis [10]. It has been reported that fatty acid induces pancreatitis in vitro [13] and ex vivo [16]. Furthermore, the dogs with pancreatitis are often obese [1]. From these investigations, it is suggested that hypertriglyceridemia resulting from obesity might be a predisposition to pancreatitis in dogs.

ACKNOWLEDGMENTS. We are grateful to Professor T. Onishi, Department of Veterinary Internal Medicine, Faculty of Agriculture, Yamaguchi University, and T. Kajikawa, Department of Veterinary Microbiology, College of Agriculture, Osaka Prefecture University, for measurement of CRP and kindly providing anti-SAA serum, respectively. 


\section{REFERENCES}

1. Anderson, N. V. 1972. Pancreatitis in dogs. Vet. Clin. North Am. 2: 79-97.

2. Attix, E., Strombeck, D. R., Wheeldon, E. B. and Stern, J. S. 1981. Effects of an anticholinergic and a corticosteroid on acute pancreatitis in experimental dogs. Am. J. Vet. Res. 42: 1668-1674.

3. Barrie, J., Watson, T. D. G., Stear, M. J. and Nash, A. S. 1993. Plasma cholesterol and lipoprotein concentrations in the dog: the effects of age, breed, gender and endocrine disease. J. Small Anim. Pract. 34: 507-512.

4. Bass, V. D., Hoffmann, W. E. and Dorner, J. L. 1976. Normal canine lipid profiles and effects of experimentally induced pancreatitis and hepatic necrosis on lipids. Am. J. Vet. Res. 37: 1355-1357.

5. Bradford, M. M. 1976. A rapid and sensitive method for the quantitation of microgram quantities of protein utilizing the principle of protein-dye binding. Anal. Biochem. 72: 248254.

6. Bronzert, T. J. and Brewer, H. B. Jr. 1977. New micromethod for measuring cholesterol in plasma lipoprotein fractions. Clin. Chem. 23: 2089-2098.

7. Chikamune, T., Katamoto, H., Ohashi, F. and Shimada, Y. 1995. Serum lipid and lipoprotein concentrations in obese dogs. J. Vet. Med. Sci. 57: 595-598.

8. Grundy, S. M. 1982. Hypertriglyceridemia: mechanisms, clinical significance, and treatment. Med. Clin. North Am. 66: 519-535.

9. Hall, J. A. and Macy, D. W. 1988. Acute canine pancreatitis. Compend. Contin. Educ. Pract. Vet. 10: 403-415.

10. Havel, R. J. 1969. Pathogenesis, differentiation and management of hypertriglyceridemia. Adv. Intern. Med. 15: 117-154.

11. MacEwen, E. G. 1992. Obesity. pp. 313-318. In: Current Veterinary Therapy XI (Kirk, R. W. ed.), W. B. Saunders Co., Philadelphia.

12. Mahley, R. W. and Weisgraber, K. H. 1974. Canine lipoproteins and atherosclerosis. I. Isolation and characterization of plasma lipoproteins from control dogs. Cir. Res. 35: 713721.

13. Nagai, H., Henrich, H., Wunsch, P-H., Fischbach, W. and Mossner, J. 1989. Role of pancreatic enzymes and their substrates in autodigestion of the pancreas. In vitro studies with isolated rat pancreatic acini. Gastroenterology 96: 838-847.

14. Poynard, T., Bedossa, P., Jais, P., Abella, A., Naveau, S., Aubert, A., Lemaigre, G. and Chaput, J. -C. 1990. Serum apolipoprotein A-I in alcoholic patients with chronic calcifying pancreatitis. Pancreas 5: 519-523.

15. Rogers, W. A., Donovan, E. F. and Kociba, G. J. 1975. Lipids and lipoproteins in normal dogs and in dogs with secondary hyperlipoproteinemia. J. Am. Vet. Med. Assoc. 166: 10921100.

16. Saharia, P., Margolis, S., Zuidema, G. D. and Cameron, J. L. 1977. Acute pancreatitis with hyperlipemia: studies with an isolated perfused canine pancreas. Surgery 82: 60-67.

17. Schaer, M. 1991. Acute pancreatitis in dogs. Compend. Contin. Educ. Pract. Vet. 13: 1769-1780.

18. Schmidt, H. and Lankisch, P. G. 1978. Fat necrosis-a cause of pancreatic parenchymal necrosis? Digestion 17: 84-91.

19. Schneider, J., Meier, M., Maroske, D. and Kaffarnik, H. 1988. Apoprotein AII in acute pancreatitis: intriguing improvement in the prediction of fatal outcome. Clinica Chimica Acta 171: 305-310.

20. Seishima, M., Torizawa, H., Saito, K., Nakamura, T., Murakami, N., Muto, Y., Nakamura, Y. and Noma, A. 1991. Serum lipid and apolipoprotein levels in patients with chronic pancreatitis. Jpn. J. Clin. Pathol. 39: 1191-1194 (in Japanese with English summary).

21. Simpson, K. W. 1993. Current concepts of the pathogenesis and pathophysiology of acute pancreatitis in dog and cat. Compend. Contin. Educ. Pract. Vet. 15: 247-253.

22. Sloop, C. H., Dory, L., Hamilton, R., Krause, B. R. and Roheim, P. S. 1983. Characterization of dog peripheral lymph lipoproteins: the presence of a disc-shaped "nascent" high density lipoprotein. J. Lipid Res. 24: 1429-1440.

23. Takeuchi, N. 1991. Metabolic disorders of lipoproteins-Influences of compositional changes of lipoproteins upon their metabolic behavior. Jpn. J. Clin. Pathol. 39: 565-573 (in Japanese with English summary).

24. Toskes, P. P. 1990. Hyperlipidemic pancreatitis. Gastroenterol. Clin. North Am. 19: 783-791.

25. Toso, C. F. R., Rodriguez, R. R., Renauld, A., Sverdlik, R. C. and Linares L. M. 1993. Blood sugar, serum insulin and serum non-esterified fatty acid levels during thiopentone anaesthesia in dogs. Can. J. Anaesth. 40: 38-45.

26. Towbin, H., Staehelin, T. and Gordon, J. 1979. Electrophoretic transfer of proteins from polyacrylamide gels to nitrocellulose sheets: procedure and some applications. Proc. Natl. Acad. Sci.U.S.A. 76: 4350-4354.

27. Whitney, M. S., Boon, G. D., Rebar, A. H. and Ford, R. B. 1987. Effects of acute pancreatitis on circulating lipids in dogs. Am. J. Vet. Res. 48: 1492-1497. 